\title{
Exploring the Use of Video-clips for Motivation Building in a Secondary School EFL Setting
}

\author{
Yujong Park ${ }^{1} \&$ Eunsu Jung ${ }^{1}$ \\ ${ }^{1}$ English Language and Literature Department, Sungkyunkwan University, Seoul, Korea \\ Correspondence: Yujong Park, English Language and Literature Department, Sungkyunkwan University, Seoul, \\ Korea. Tel: 82-2-760-0255. E-mail: yujpark@skku.edu
}

Received: July 31, 2016 Accepted: August 31, 2016 Online Published: September 2, 2016

doi: 10.5539/elt.v9n10p81 URL: http://dx.doi.org/10.5539/elt.v9n10p81

\begin{abstract}
By employing an action research framework, this study evaluated the effectiveness of a video-based curriculum in motivating EFL learners to learn English. Fifteen Korean EFL students at the secondary school context participated in an 8-week English program, which employed video clips including TED talk replays, sitcoms, TV news reports and movies as its main study material. Results from the motivation surveys (adapted from Gardner, 1985) and interviews with students showed that 1) after taking the class, students became more motivated, especially in terms of gaining a positive attitude for the English language and culture, and 2) competitive group activities that followed the watching of video materials positively influenced student participation. Implications for EFL classrooms with low student motivation are discussed.
\end{abstract}

Keywords: video materials, EFL motivation, action research, Korean secondary students

\section{Introduction}

\subsection{Background}

Motivating EFL students to learn English can be a challenge for instructors teaching required English classes at secondary school settings. In Korea, which provides the location for this study, English is taught as a mandatory subject for all high school students. Although English is considered as one of the main subjects for entering the local university (along with Korean and math), students do not see much usage for the English subject outside of the classroom, which is reflected in their low motivation for learning English when compared to other countries (Kim, 2006). According to Kim (2006), Korean EFL students' motivation is affected by negative wash-back from the College entrance exam (i.e., CSAT) and anti-American sentiment, which he describes as being Korean-specific. In particular, secondary school teachers face a challenge in motivating their students to participate in English classroom activities (Han, 2014). This study, thus, began with the larger question of "How can we make EFL students participate more in the classroom and become more motivated to learn English?" This led us to consider video clips as a way of encouraging and motivating this body of students.

Findings from previous studies provide support for students wanting to have more video materials (i.e., video clips) embedded in their classroom (Berk, 2009; Goldstein \& Driver, 2015). The introduction of video materials into the curriculum has often been advocated for its value in teaching L2 culture (Herron et al., 1999) and in learning vocabulary (Lee, 2004; Vidal, 2011). However, not many studies have investigated the role of video material in building motivation in the Korean context (cf., Han, 2014), possibly due to the difficulty in designing a video based curriculum. Different types of video material are easily accessible through mobile devices (e.g., YouTube), and teachers can choose from a rather varied set of material depending on the learner's age and language proficiency. However, a video-based curriculum in L2 classrooms is difficult to find, despite its putative role in motivation building, primarily due to the difficulty of classroom implementation in a teacher-centered classroom, the effort needed to simplify or prepare appropriate video clips, and lack of resources (Sherman, 2003). Teachers voice a need to adopt visual materials in their curriculum (Han, 2014); however, there appears to be a gap between an ideal and the actual practice.

\subsection{Purpose}

In this study, we report on the effectiveness of a video-based curriculum in motivating Korean secondary school EFL students by employing an action research framework. Our main goal was to investigate whether students 
learning the English language via an 8-week class period that employed video clips as its primary tool for instruction will experience beneficial gains in motivation and participation. We accomplished this aim by means of using popular English animations, films, TV news reports and sitcoms and building interactive tasks around these materials. We administered two sets of motivation surveys and selective interviews before and after the instruction period to examine whether the use of visual materials changed the attitudes of the participating students. We also analyzed selected episodes of classroom interaction to see whether there were changes in student participation. We believe the findings may have implications for teachers working in other EFL secondary school contexts similar to the Korean setting in terms of lack of motivation and lack of opportunities outside of the classroom to practice the new language.

The research question for this study can be summarized as following:

1) How did the motivation of the target students toward learning English change after the eight-week period of using video clips?

2) How did the participants perceive the designed video-clips curriculum?

3) How did the content of student interactions change after the eight-week experiment?

\subsection{Literature Review}

L2 motivation is a complex concept with many sub-constructs and levels. According to Gardner (1985), motivation is "the combination of effort plus desire to achieve the goal of learning the language plus the favorable attitudes toward learning the language." (p. 10) This definition has theoretically expanded in recent models of L2 motivation, such as the process model (Csizér \& Dörnyei, 2005; Dörnyei, 2005) as different types of L2 motivation can be generated, maintained, and terminated depending on learners' varied L2 learning experiences. Studies on L2 motivation have increased over the years with the recognition that L2 motivation can be influenced by school teachers and environmental factors whereas there is little possibility for change in language aptitude or verbal intelligence (Christophel \& Gorham, 1995; Kim, 2005). For example, the possibility exists that L2 learners who initially show lack of motivation will later become highly motivated students in language learning. In this sense, changes in L2 motivation is worth studying through an action research framework, by studying the effect of a particular instructional method for the enhancement of L2 motivation (Dörnyei, 2001). This study employed an action research framework, which we decided to be most appropriate in addressing the research question above and in revealing a more in-depth analysis of student motivation. It can also provide an alternative to the reductionist conceptualizations of L2 motivation by investigating qualitative experiences of L2 learners in real time classrooms (Kim, 2005).

Although the model is criticized on several notes, L2 motivation research is heavily influenced by Gardner's research on the role of attitude and motivation in L2 learning (Gardner, 1985; Gardner \& Lambert, 1972 inter alias). This research can be summed up as follows (Kim, 2005, p. 301):

1) L2 learning motivation can be divided into integrative and instrumental orientation (later termed orientation)

2) A crucial factor of L2 learners' proficiency is not instrumental motivation but integrative motivation

3) The attitudes toward the target language community and L2 native speakers are incorporated into the umbrella concept of motivation

Since Gardner's initial studies in the 1990s, different motivational concepts have been added over the years. For example, the construct of self-confidence and the appraisal of the classroom environment (Clement, Dörnyei \& Noels, 1994), persistence, attention, goal specificity, and causal attribution (Tremblay \& Gardner, 1995) are several of those added concepts. MacIntyre (2002) predicted that studying the variables identified as motivational components would keep the L2 motivation field busy for a very long time. However, Gardner's model provides a nice baseline to these additions (MacIntyre, 2002); thus, we decided to adapt his additional questionnaire items in constructing our own motivational survey (Appendix A). Kim (2005) used a Kuhnian analogy to describe the period before Gardner's model as the pre-scientific period, and Gardner's proposal of the socio-educational model in 1985 as the Kuhnian scientific phase. Most previous L2 motivation literature used data based on questionnaire surveys collected from participants by adapting Gardner's categories (1985) to investigate the statistical significance of the data collected. It is hypothesized that these quantitative methods can provide clues to understanding human motivation.

Action research is a teacher-initiated research in which teachers critically evaluate their classrooms for the purpose of improving their own teaching and enhancing the quality of student learning (Grabe \& Stoller, 2002; Wyatt, 2010). It typically involves systematic observations and data collection, which can be then used by the 
practitioner-researcher in reflection, decision-making and development of more effective classroom strategies (Parsons \& Brown, 2002). This type of research is valuable because it can be repeated until teachers find a solution to their professional practice. In other words, since it can be cumulative, the research not only can be continued, but can provide a valuable source as well. We hoped that the current study could provide a preliminary picture of the value of using video clips in EFL learning and teaching by employing an action research framework.

\section{Method}

\subsection{Participants}

Fifteen high school students from a national high school located at a city in South Korea participated in an 8-week "Have fun with English" class, with the title that we thought would be most appropriate. English was a required subject for all students attending this high school. The instructor taught the target classes based on visual materials every Saturday for eight weeks during the spring semester of 2013, with each class lasting for about 90 minutes (from 10 to 11:30 AM). The students participated on a voluntary basis, and the classes offered free material including textbooks and classroom aids. Homeroom teachers encouraged their students to take this English class and in the end, a total of 15 students (13 female and 2 male students) participated. The English proficiency of these students could be considered intermediate based on their mid-term average score (86.6 out of 100). We were unable to collect official English test scores as these students were too young and had no specific reason to take TOEFL or TOIEC tests yet.

\subsection{Procedures and Materials}

We developed a syllabus for this group of Korean high school students featuring tasks and activities based on video materials. The reasons for developing our own materials (i.e., textbooks and visual data) were: 1) no currently available high school textbooks used video materials as its main material; 2) among a wide range of video clips only those materials that were appropriate for these cohort of students needed to be chosen (e.g., motivating and appropriate for high school students with intermediate English proficiency; 3) in addition to the video materials, tasks and activities surrounding these materials needed to be developed. Our primary aim was to investigate whether video-clips would facilitate student motivation in learning English, and lead to more active participation.

The video material included sitcoms, movies, TED presentations and television news reports. Short conversational extracts from the American sitcoms "Friends", and "Modern Family", TED Talks titled "How School Kills Creativity" and "Your Body Language Shapes Who You Are," short clips from movies "Avengers" and "the Frozen," and finally a clip from the CBS News program titled "New Fat Cats and Pudgy Pooches." This material was selected after interviewing several high school students and carefully considering what would interest the EFL students. Copyrights for some of the video material (e.g., "Friends," and "Avengers") were considered by not showing more than five minutes of each film in the class. The resulting textbook consisted of 45 pages, which included scripts, vocabularies, grammar and expressions, and activities. The content of the textbook for one of the classes are provided in Table 1.

Table 1. Content of the textbook for week 4

\begin{tabular}{lll}
\hline Visual material & Title & Textbook content \\
\hline \multirow{2}{*}{ TED Talk } & How school kills creativity & - Script in both English and Korean \\
& by Ken Robinson & - Expressions and vocabulary \\
& - Group discussion questions \\
& - Pop quiz (group competition) \\
\hline
\end{tabular}

A typical lesson began with a review of previously taught material. Next, after new target language (vocabularies and structure) was introduced, students watched video clips several times along with the English subtitles and Korean translation (which was provided in their textbook). Key expressions and vocabulary were taught by the instructor. Various group activities and games followed. Vocabulary was taught because prior studies have reported the beneficial effects of using video clips in learning words (Jung \& Lee, 2013). Group activities included simple roleplaying using the dialogue provided or discussing the topics in lieu of their own personal experiences (e.g., "What would you do if you were Joey?"; "Do you think there are some selfless good deeds?", and "What do you think good education is?"). Students were asked to sit in groups of 4 to 5 when they entered 
the class, so that they could engage in effective group work. Finally, the teacher gave a pop quiz (with a prize to the winning group), which resulted in groups competing with each other to win the prize. After a 5-minute break, another 40 minute class ensued, following the same order as above.

\section{Results and Discussion}

To evaluate the effectiveness of the video-based class (and the action research) from various perspectives, three kinds of data were gathered. Two questionnaires (adapted from Gardner 1985), one administered at the beginning and one at the end of the instructional period, were used to understand and gauge students' motivational changes. The survey consisted of 14 questions and was developed to measure students' motivation on learning English, including questions on positive attitudes, negative attitudes, desire and willingness, and level of confidence. Interviews with students were also conducted before and after the entire period to capture the students' expectations as well as reactions to the video material and classroom procedures. Finally, video recordings were made of the classroom sessions to gain insight into teacher-student interactions occurring during the class as well as the extent of the students' ongoing development.

\subsection{Results from the Motivation Questionnaires}

We administered two motivation questionnaires in Korean (see Appendix 1) to the students containing 14 five-item Likert-scale questions covering four sub-categories: 1) positive attitudes toward learning English, 2) negative attitudes toward learning English, 3) desire and willingness toward learning English and 4) student level of confidence. Although the use of quantitative research methodology to investigate language learners' motivation has been criticized on several counts (Dörnyei, 2001; Kim, 2005, 2006), questionnaire surveys were administered in order to gain a simple understanding of the link between a specific instructional method and motivation. We wanted to see how the students' motivational attitude changed after they took this class. Evaluating motivational change was important to us because our entire effort was based on the belief that providing video materials to these EFL secondary school students would result in a positive change in their attitude toward English. The results of the pre- and post- surveys were compared using a t-test. The results of the t-tests are shown in Table 2. Significant changes are bold faced. A total of 6 questions out of 14 displayed changes in motivational attitude.

Table 2. T-test results for the pre- and post- survey on motivation

\begin{tabular}{lllll}
\hline Questions & $\mathrm{t}$ & $\mathrm{Df}$ & $\mathrm{MD}$ & $\mathrm{P}$-value \\
\hline Positive attitude questions & & & & \\
\hline 1. Learning English is really fun. & -2.570 & 28 & .743 & $\mathbf{. 0 1 6}$ \\
\hline 2. I really enjoy learning English. & -3.034 & 28 & .724 & $\mathbf{. 0 0 5 *}$ \\
\hline 3. English is very important part of the school program. & -.316 & 28 & .640 & .754 \\
\hline 4. I plan to learn as much English as possible & -1.742 & 25.321 & .724 & .301 \\
\hline Negative attitude questions & & & & \\
\hline 1. I hate English. & -2.246 & 28 & .640 & $\mathbf{. 0 3 3 ^ { * }}$ \\
\hline 2. I would rather spend my time on subjects other than English. & -1.871 & 28 & .724 & .072 \\
\hline 3. I think that learning English is dull. & -2.827 & 28 & .743 & $\mathbf{. 0 0 9 *}$ \\
\hline Desire and willingness questions & & & & \\
\hline 1. I have a strong desire to know all aspects of English. & -1.488 & 28 & .594 & .148 \\
\hline 2. If it were up to me, I would spend all of my time learning English. & -1.722 & 24.445 & .834 & .072 \\
\hline 3. I want to learn English so well that it will become natural to me. & -1.521 & 28 & 1.187 & .139 \\
\hline 4. I want to speak English fluently. & -1.058 & 23.458 & .258 & .148 \\
\hline 5. Knowing English isn't really an important goal in my life. & -1.449 & 28 & .828 & .158 \\
\hline 6. I sometimes think of giving up English learning. & -1.544 & 18.754 & .258 & $\mathbf{. 0 0 9 *}$ \\
\hline Confidence & & & & \\
\hline I think I am afraid of meeting a native speaker. & -5.332 & 28 & .926 & $\mathbf{. 0 0 0 *}$ \\
\hline$* p<.05$. & & &
\end{tabular}


Among the four items asking for positive attitude on learning English, the first two questions ("Learning English is really fun" and "I really enjoy learning English") showed a positive and meaningful change. After the 8-week program, more students agreed that learning English is fun and that they enjoyed learning English. Item 3 ("English is a very important part of the school program") did not show a meaningful change as most of the students already agreed in the pre-survey that English is a very important part of their school curriculum. In general, students showed a more positive attitude towards the English language after the 8-week program.

The students' negative attitudes appeared to be the most strongly affected category by the employment of video clips as two out of the three items showed a significant difference between the pre- and post- survey. A significantly smaller number students agreed to "I hate English" and "I think that learning English is dull" after taking this class. This is very important because prior to taking the class, about $14 \%$ of the students reported that they hated English. This number was reduced to 0 after the 8 -week period. Table 2 also shows that the students' desire to learn English was heightened after the class as fewer students answered, "I sometimes think of giving up English learning," showing a significant difference in response frequency. Finally, the students' confidence grew in terms of conversing with a native speaker. Many students checked that they were afraid of meeting a native speaker (73\%) in the pre-survey whereas in the post survey only $7 \%$ of the students agreed to this question $(\mathrm{p}<.05)$

Overall, Table 2 highlights a positive change regarding motivation after the 8-week instructional period, particularly in terms of changes in attitudes towards learning English. This is very important, because it shows that even a short-term instruction of two months can have such a meaningful impact on these EFL students. The results of the survey were complemented by student interviews which are reported in the following section.

\subsection{Student Interviews - Motivation and Participation}

Many students when asked about what they liked most about this class answered that the classroom materials were the most interesting aspect of the class. The following student reported on the benefits of visual materials in terms of motivation to learn the language:

I was motivated, because we studied with the movie and the sitcom, which is very interesting. I think I will study English more because now I want to know about the language. (S3)

The following students report that the sitcoms motivated them to learn more about the American culture and also to learn on their own (i.e., by watching TED talks). These accounts reveal that video-clips can encourage learner autonomy in language learning:

It was very exciting to guess the meaning of new expressions that I have never heard of. Also, watching the sitcom was very motivating for me to study English harder, because now I really want to know about their culture and speak fluently like characters in the sitcom. (S4)

When I saw the movie and the sitcom, I realized how it would be great to speak fluently and understand without a subtitle. So I started watching the TED talks, which the teacher suggested us to watch, and it was very motivating and helpful as watching those speeches has broadened my eyes. I want to speak in front of many people, like speakers in the TED talks. (S5)

I sometimes watched videos that teacher gave me just because it was fun to watch. I think that is the main reason why my English improved a lot. (S7)

At the end of the session, five (out of the fifteen) students reported that they liked this class because they had more chances to participate. Participation may have been promoted by the use of group activities that required students to compete in groups through games. The winning group was always rewarded with a small prize (e.g., candies, chocolates) and this seemed to promote lively and active participation:

I liked the fast-speaker game the most. Before I took this class, I thought my pronunciation was not good enough, so I was afraid of speaking English in front of many people. However, when I practiced Joey's line to win this game, I realized my pronunciation got better and better. (S11)

Prior studies on Korean high school students have revealed that these students have high "competitive motivation" (Lee, 1996; Kim, 2006, p. 180), which is defined as the desire to obtain relative superiority to peers. The results of this study support the existence of a 'competitive motivation' in Korean high school students when learning L2 English. This could be a topic for further investigation in future studies on types of motivation.

\subsection{Classroom Observation Results from Video Data}

The final research question was addressed by studying the recorded data from the 8-week program. Although we cannot make quantitative claims, the frequency of interactions occurring in English appeared to increase 
throughout the period. The value of group work and competition in drawing participation could be noted, in particular. The result showed that competition among groups played a huge role in drawing participation among students in terms of speaking as shown in the following interaction. Students formed three groups and solved the discussion questions on the TED talk as provided in the textbook. One presenter gave a speech in front of the classroom and the rule was to use at least three English words in the presentation. Students participated in the activity to win the group competition. The target English words are bold faced (i.e., first, presentation, teacher, and communication) in the transcript. The second line provides the Yale morpheme-by-morpheme transcription. Pauses and speech perturbations are not reflected in the English translation (third line).

\section{Extract 1. TED class2}

$01 \mathrm{S1} \quad \quad$ (2.0) wusen (1.0) cehuico-nun (0.3) first (hh) il::cwuiley han penssik (2.0) first (1.0) our group-TOP (0.3) first (hh) one week-at once "At first our group thought first hhhh once a week"

02 (0.3) cikcep cheyhum-ul hako .hh (1.0) presentation-kwa (0.5)

(0.3) direct experience-ACC do .hh (1.0) presentation-and (0.5) "having direct experience and .hh giving presentation and"

03 teacher-waui hhh communication::-ul .h mani hanun ket-i.

Teacher-with hhh communication::-ACC .h a lot do thing-NOM "engaging in many communication with teacher"

04 (0.5) milay-ui? Wuli:: nalaui coun (0.2) kyoyuk-ilako sayngkak-hamnita.

(0.5) future? Our:: country good ( 0.2$)$ education-QT think-DC

"That's good education of Korea for the future."

$05 \mathrm{~S} 2: \quad$ (0.2) cehui co-nun, (0.2) e:: (0.5) chapwel epsnun education-ul

(0.2) out group-TOP, (0.2) umm:: (0.5) unbiased education-ACC

"Our group. unbiased education would"

06 hanun ket-ul e:: 0.3) coh-tako sayngkak-hayss-nuntey? (1.0)

Do thing-ACC mm:: (0.3) good-QT think-but? (1.0)

"be a good thing?"

$07 \quad$ (0.5) haksayngtul-eui sengcek-ul, tungkup-ulo (0.2) nanu-ci ahn-ko .hh

(0.5) students' grade-ACC, grades (0.2) divide NEG-and .hh

"Rather than dividing students into grades"

08 (hh) all students (h)-eykey? kongpyeng-han kihwey-lul cwu-nun ket-ul (0.3)

(hh) all students (h)-to? Fair change-ACC give thing-ACC (0.3)

"giving all students fair chance"

09 e:::> kongpyeng-han kihwey-lul cwu-nun kyoyuk-ul< hamyen .hh

mm::: > giving fair change education $<$ do.$h \mathrm{~h}$

"would be good education"

10

(0.2) cuhkeyss-tako saynkak-[hamnita

(0.2) good-QT think-DC

"in our opinion"

$11 \mathrm{~T}: \quad$ [okay good. hhh

Here, students are using at least three English words that they have learned in their presentation on behalf of their group members to talk about "what good education means for them." The point of the group activity was not to improve their speaking ability per se, but to encourage students to speak out in the classroom (i.e., voice 
their opinions) since students were accustomed to being silent during the class (Tsui, 1996). The students and the teacher could choose between Korean and English. Here, the teacher uses English to provide an evaluation at line 11 ("okay good") while the students mostly use Korean with some English words. Students who did not speak out in the beginning participated more during the final weeks. The following excerpt from a student interview shows that this class helped in promoting more speech.

I liked the class, because I have never had a chance to speak or make a presentation for the class. But in this class, I could speak about my opinions freely. Also, I feel like my listening has improved. (S1)

We were unable to collect student interaction prior or after this 8-week course to make any meaningful comparison due to the nature of the classroom (i.e., students took this class as a summer school optional program and went back to their own separate classrooms afterwards). Future studies may collect further data from classroom interactions prior and after the use of video clip materials to make meaningful comparisons.

\section{Conclusion}

The design of the class was motivated by the recent shift in focus in L2 teaching and learning; this was from emphasizing texts to the recognition that multimedia such as video clips may be helpful and even essential in language learning. The main pedagogical implication of the present study is the effectiveness of video clips in increasing student motivation. In any EFL program targeting secondary students, one of the biggest challenges facing teachers is to get the students to participate in the class and to be interested in learning the English language. The present research shows the value of visual materials in promoting student motivation, which includes interest in the language, culture and also for increasing student participation. This action research also suggests that language teachers should try to develop some of their own materials for motivating their students and to reflect on the current interests of the students.

Another implication of the study is related to the positive, reinforcing, effect of video materials on the learning of culture. Based on this finding, teachers might consider the value of visual materials in teaching L2 culture. Overall, this study has shown that teaching English by using video clips is effective in improving student motivation and drawing out participation. To address the previous research questions, the use of video clips for EFL secondary school students appears to help improve motivation and participation. This small-scale action research (focusing on one high school class in the context of South Korea and East Asia) provides evidence that incorporating video material into L2 classrooms can be beneficial.

There is, however, a caveat in order. Teachers who use similar materials would not necessarily achieve the same outcome. Individual differences are crucial and different student groups might experience different results. This study only explored one body of students, therefore, further studies on students' motivation development using video material needs to be conducted to quantitatively explore the effectiveness of the instructional model by using video clips with different students. Nevertheless, the research presented here has highlighted the possibility that an increase in motivation in a relatively short period of time is achievable with the use of video clips. In this sense, this article provides a meaningful contribution to future directions for teaching in EFL contexts using video material and also for the promotion of action research by showing that it is possible and even beneficial to answer practical questions that arise while you teach your own L2 classroom.

\section{References}

Berk, R. (2009). Multimedia teaching with video clips: TV, movies, youtube, and $\mathrm{mtvU}$ in the college classroom. International Journal of Technology in Teaching and Learning, 5(1), 1-21.

Christophel, D. M., \& Gorham, J. (1995). A test-retest analysis of student motivation, teacher immediacy and perceived sources of motivation and demotivation in college classes. Communication Education, 44, 292-306. http://dx.doi.org/10.1080/03634529509379020

Clement, R., Dörnyei, Z., \& Noels, K. (1994). Motivation, self-confidence, and group cohesion in the foreign language. Language Learning, 44(3), 417-449. http://dx.doi.org/10.1111/j.1467-1770.1994.tb01113.x

Csizér, K., \& Dörnyei, Z. (2005). The internal structure of language learning motivation and its relationship with language choice and learning effort. Modern Language Journal, 89, 19-36. http://dx.doi.org/10.1111/j.0026-7902.2005.00263.x.

Dörnyei, Z. (2001). Motivational strategies in the language classroom. Cambridge, UK: Cambridge University Press. http://dx.doi.org/10.1017/CBO9780511667343

Dörnyei, Z. (2005). The psychology of the language learner: Individual differences in second language acquisition. Mahwah, NJ: Lawrence Erlbaum. http://dx.doi.org/10.1177/0261927X05281424 
Gardner, R. C. (1985). Social psychology and second language learning: The role of attitude and motivation. London: Edward Arnold.

Gardner, R. C., \& Lambert. (1972). Attitudes and motivation in second-language learning. Mass.: Newbury House Publishers.

Goldstein, B. \& Driver, P. (2015). Language learning with digital video. U.K.: Cambridge University Press.

Grabe, W., \& Stoller, L. (2002). Teaching and researching: Reading. Harlow, England: Longman.

Herron, C., Cole, S., Corrie, C., \& Dubreil, S. (1999). The effectiveness of a videobased curriculum in teaching culture. The Modern Language Journal, 83(4), 518-533. http://dx.doi.org/10.1111/0026-7902.00038

Han, J. I. (2014). The effects of learning models of English digital textbooks on Korean middle school students. Multimedia-Assisted Language Learning, 17(1), 132-158.

Jung, R., \& Lee, C. H. (2013). Using Internet video clips for university students' vocabulary development in blended learning. Multimedia-Assisted Language Learning, 16(4), 67-96.

Kim, T. Y. (2006). Motivation and attitudes toward foreign language learning as socio-politically mediated constructs: The case of Korean high school students. The Journal of Asia TEFL, 3(2), 165-192. http://dx.doi.org/10.1007/s12564-010-9071-7

Kim, T. Y. (2005). Reconceptualizing L2 motivation theory: Vygotskian activity theory approach. English Teaching, 60(4), 299-322. http://dx.doi.org/10.15858/engtea.68.4.201312.141

Lee, C. H. (2004). The effective use of live and recorded video on Satellite TV and the Internet in FLT/L. Multimedia-Assisted Language Learning, 7(1), 83-108.

Lee, H.-W. (1996). The effects of attitudes and motivation on learning English in Korean secondary school students. English Teaching, 52, 3-34.

MacIntyre, P. D. (2002). Motivation, anxiety and emotions in second language acquisition. In P. Robinson (Ed.), Individual differences and instructed language learning (pp. 45-68). Philadelphia, PA: John Benjamins. http://dx.doi.org/10.1075/11lt.2.05mac

Masgoret, A., \& Gardner, R. C. (2003). Attitudes, motivation and second language learning: A meta-analysis of studies conducted by Gardner and associates. Language Learning, 53(1), 123-163. http://dx.doi.org/10.1111/1467-9922.00227

Parsons, R. D., \& Brown, K. S. (2002). Teacher as reflective practitioner and action researcher. Belmont, CA: Wadsworth.

Sherman, J. (2003). Using authentic video in the language classroom. Cambridge: Cambridge University Press.

Tsui, A. B. M. (1996). Reticence and anxiety in second language learning. In K. M. Bailey, \& D. Nunan (Eds.), Voices From the Language Classroom (pp. 145-167). Cambridge: Cambridge University Press.

Vidal, K. (2011). A comparison of the effects of reading and listening on incidental vocabulary acquisition. Language Learning, 61, 219-258. http://dx.doi.org/10.1111/j.1467-9922.2010.00593.x

Wyatt, M. (2010). Teachers researching their own practice. ELT Journal, 65(4), http://dx.doi.org/10.1093/elt/ccq074 


\section{Appendix A}

\section{Pre- and Post-motivational Survey}

Please write down the number that describes you best. 번호를 매겨주세요!

\begin{tabular}{|l|l|l|l|l|}
\hline $\begin{array}{l}\text { 1. 매우 그렇다 } \\
\text { Strongly agree }\end{array}$ & 2. 그렇다 & 3. 그저 그렇다 & 4. 아니다 & 5. 매우 아니다 \\
Neither agree nor disagree & Disagree & Strongly disagree \\
\hline
\end{tabular}

1. Learning English is really fun.

2. I really enjoy learning English.

3. English is a very important part of the school program.

4. I plan to learn as much English as possible.

5. I hate English.

6. I would rather spend my time on subjects other than English.

7. I think that learning English is dull.

8. I have a strong desire to know all aspects of English.

9. If it were up to me, I would spend all of my time learning English.

10. I want to learn English so well that it will become natural to me.

11. I want to speak English fluently

12. Knowing English isn't really an important goal in my life.

13. I sometimes think of giving up English learning.

14. I am afraid of meeting a native speaker.

\section{Copyrights}

Copyright for this article is retained by the author(s), with first publication rights granted to the journal.

This is an open-access article distributed under the terms and conditions of the Creative Commons Attribution license (http://creativecommons.org/licenses/by/4.0/). 